\title{
Collaborative Development of Innovation Industrial Agglomeration and Urbanization
}

\author{
Yu Huixin \\ School of Economic and management \\ Hebei University of Technology \\ Tianjin China \\ yuhuixincn@126.com
}

\author{
Xia Zheng \\ School of Economic and management \\ Tianjin College of Commerce \\ Tianjin China \\ Xiazheng22@126.com
}

\author{
Ma Zhidong \\ School of Economic and management \\ Hebei University of Technology \\ Tianjin China
}

\begin{abstract}
Based on innovative industry agglomeration, this research analyzes the main elements and components of innovative industry agglomeration area. The formation of innovative industry agglomeration and development of urbanization go hand in hand. Innovative industry agglomeration plays an important role in promoting the construction of urbanization which promotes innovative industry agglomeration as well. It explores the collaborative development of innovative agglomeration area and construction of urbanization.
\end{abstract}

Keywords-innovative industry agglomeration; urbanization; elements; collaborative development

\section{INTRODUCTION}

Industry agglomeration refers to the same industry highly concentrated in a specific geographic area, a process of elements of industrial capital continuously converged within space, and it reflects human agglomeration, spatial concentration through industrial clustering so as to realize healthy development of the industrial chain and intensification As a new form of industrial organization, industry agglomeration area plays an important role in promoting industrial innovation and competitiveness of the regional economy and impacting on the sustainability of regional economic development, through knowledge and technology spillover effect, scale economy, scope economy, collaborative effect and so on.

Relying on industry agglomeration area, innovative industry agglomeration area takes institutional and technological innovation as the key driving force, effectively gathers resources and innovative elements to form dominant industries characterized by cluster development of high-tech enterprises and high processing enterprises or fully reflects upgrading traditional industries by using high technology, and then forms technology service system and quality management system supported by enterprise innovation. It is the bases of development of strategic emerging industries and high-tech industries [1]. Through optimizing the allocation of innovative resources in agglomeration area and creation, dissemination, introduction, diffusion and application of new technologies, knowledge, techniques among the various components of innovative system in the agglomeration area, it promotes sustainable economic growth and industrial structure of the cluster optimization, and its core is to achieve close links between the main cluster of innovation and organic interaction,

Supported by Soft Science Project of Hebei Office of Science and Technology: Collaborative development of Innovation industrial agglomeration and Urbanization. (14456115D) so that the flow of knowledge and technology is effectively and fully diffused inside the cluster innovative system, truly served to strengthen the core competitiveness of enterprises, and then enhance the competitive advantage of the agglomeration.

With the rapid growth of economy in China, urbanization becomes the trend of economic development and important engine of future economic growth. Urbanization refers to the process of rural population engaged in primary industry turning into the urban population engaged in secondary and tertiary industry. The essence of urbanization is the transformation of space population, economic structure, and then becomes the gathering center of economic activity.

\section{ELEMENTS OF INNOVATIVE INDUSTRY AGGLOMERATION AREA}

Numerous elements gather together and form innovative industry agglomeration area, each of which includes a number of sub-elements. Each element has different functions, and sub-element has the function of location compared to other sub-elements. These elements are connected by a certain mechanism, organic complex; continuously promote the best allocation of innovative resources so as to enhance the competitive advantage of agglomeration. Generally, the elements of innovative industry agglomeration area are divided into three levels:

\section{A. Core elements of innovative industry agglomeration area}

Core elements of an innovative industry agglomeration area include the suppliers in the area, finished product manufacturers, distributors in the cluster, universities and research institutions within the cluster. These elements form the main body of innovation system in the area; realize the interaction through industry value chain, that is, links of competition and cooperation or other internal connection modes.

Among the core elements, the finished product manufacturing enterprises are the main organizers, implementers and the ultimate achievers of innovation achievements [2]. Supplier companies within the cluster are providers of innovative resources, sometimes also the initiators of innovative activities, motivators, guides and organizers (such as planning and implementing a number of significant technology projects to the economic development of the cluster). Universities and research institutions are the providers 
of innovative technology, cultivators and suppliers of innovative personnel.

\section{B. Auxiliary elements of innovative industry agglomeration area}

The elements of auxiliary level in innovative industry agglomeration area mainly include: hardware technology infrastructure, agencies and public institutions. The elements of auxiliary level provide services for innovation in core layer, such as innovative hardware service, innovation and infrastructure service, human resource service, technical knowledge exchange service and financial service, etc. It is the protection of industrial clusters innovation. The elements of auxiliary level provide services for the continuous innovative output of cluster-level innovative system, and lose the meaning of existence without the core layer elements.

The value of sub-element of auxiliary level is in innovative industry agglomeration area. Cluster agencies serve as a bridge and link of the innovation activities in cluster system, in the role of information centers, training centers, consulting firms, broker organizations, technology assessment agencies, technical dispute arbitration institutions, industry associations, and so on. Financial institutions of public service agencies are the main funding suppliers of innovative and industrial agglomeration [3]. Legal aid institutions in the agglomeration help agglomeration members to apply and protect the product patent. Human service agencies in the agglomeration introduce and give training to the high tech talents.

\section{Macro environmental elements of innovative industry agglomeration area}

Macro environmental elements of innovative industry agglomeration area involve policies, laws and regulations, taxation and financial systems environment, and social credit environment, innovative and cultural environment and external markets in the area. These elements constitute the external environment of innovative industry agglomeration which acts on the innovative activities. But these elements also exist without the cluster. Therefore, these elements are not controllable in the agglomeration.

\section{1) Innovative industry.}

The formation of innovative industry agglomeration is inseparable from the powerful support of innovative industries and supporting industry clusters, which accelerate the process of innovation, promote to achieve the competitive advantage of agglomeration area. The rapid development of information technology industry promotes the emergence of new ideas, technologies, mode of operation, new operation and services, and then becomes catalyst for innovative industry agglomeration area.

\section{2) Demand condition}

The products of innovative industry include the basic material products, spiritual, cultural, and entertainment products. With the improvement of people's living standards, the demand for spiritual products is rising in general, and the demand is growing, which is the fundamental reason of innovative industry development.

\section{3) Development strategy.}

Regional development strategy consists of business strategy, competition and cooperation, etc. According to close integration of culture and economy, the strategic planning of the enterprises in the agglomeration area is based on the existing market and development of product and services on local culture, and focus on the value of innovation of established goods and services.

\section{4) Regional culture.}

Cultural Factors of innovative industry agglomeration area play significant role in reconstruction of regional culture, and embody key role of cultural and personal factors in economic and social development.

\section{5) Governmental mechanisms.}

With a strong ideological attributes, innovative industries are inextricably linked with a country's economy, ideology, tradition and culture. Compared with general industries, the links between government and innovative industries are more closely. Therefore, to gather and promote the rapid development of innovative industries, it must promote the competitive advantage and attach great importance to the function of government.

\section{THE INTERACTION BETWEEN URBANIZATION AND INNOVATIVE INDUSTRY AGGLOMERATION}

Innovative industry agglomeration promotes the formation and development speed of the elements required for urbanization, and further development of urbanization, puts forward higher requirements for urban spatial expansion. At the same time, urbanization provides spatial carrier of innovative industry agglomeration development, and it is a strong support for development of innovative industry agglomeration. Therefore, the relationship between industry agglomeration and urbanization is to promote each other and coordinated develop [4].

The interaction between urbanization and innovative industry agglomeration is in the following Fig. 1.

\section{A. The effects of urbanization to innovative industry agglomeration}

It proves that the development of regional industry has a very high degree of dependence on the process of urbanization from theoretical analysis and real cases. A large variety of different types and levels of economic activity and consumer demand are from the city with crowded people and many social and economic activities, thus provide an effective power and conditions for gathering and development of innovative industries.

The effects of urbanization to innovative industry agglomeration are embodied in the following four aspects [5]:

Firstly, the accumulations of population elements in the process of urbanization directly reduce the costs of innovative industry accumulation. At the same time, various elements are 


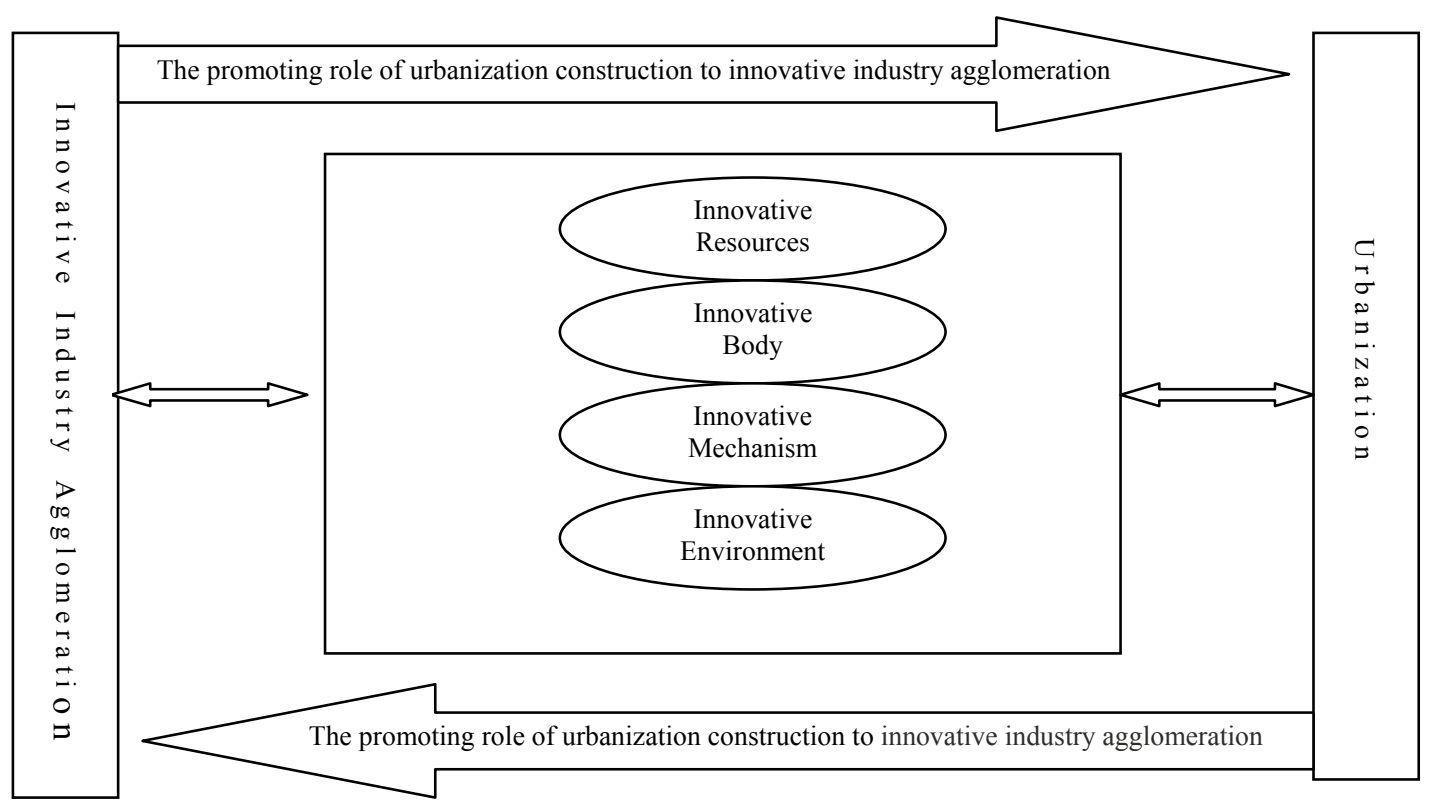

Fig. 1. The interaction between urbanization and innovative industry agglomeration

gather together and through highly specialized division of labor and mutual cooperation, and form the complex links of various elements in the network, promote the development of capital market, means of production market and the commodity markets, then reduce the transaction costs.

Secondly, higher level of urbanization can promote deeper specialization of innovative industry agglomeration, promote transition of innovative industry agglomeration from a full-type industry cluster to chain industry cluster, and achieve division of labor and cooperation of enterprises within wider region.

Thirdly, by using the extended geographical space, urbanization optimize the industrial structure and spatial structure within the city to a higher level of development in innovative industry agglomeration, thereby form a continuous expansion of urban scale, continue to strengthen diffusion, give full play to virtuous cycle of effects of urbanization to innovative industry agglomeration [6].

Fourthly, the formation of regional brand not only improves the competitiveness of cities and small towns but also improve the competitiveness of industrial agglomeration.

Development of urbanization also promotes the construction of innovative industry agglomeration area. The process of new urbanization is the aggregation process of human resources, economic factors of production and spatial agglomeration of technical resources. Therefore, the development of urbanization is the aggregation by gathering people together to drive the talents, technology resources, industry, land resources, the accumulation factors of production, and the promotion of technological innovation and enhance regional economic development, optimize the industrial structure, promote the intensive use of resources and conservation, then increase economic efficiency. Urbanization directly provide the developing platform to the development of the secondary and tertiary industries, and it also created external economic effects of the second and tertiary industries in developing environment, such as improving quality of labor, public service facilities and perfection of information services work.

Thus, to achieve cluster development in the economy is the fundamental point of new urbanization. The urbanization cluster development can provide adequate human resources for construction of innovative industry agglomeration area, and even economic factors of production and technical resources for the constructions. Most importantly, with the development of new urbanization, urban infrastructure in surrounding areas such as transportation, communications will gradually improve and develop, which build a bridge for industry agglomeration area to the market [7].

Improving the urbanization level will promote sound development of the industry agglomeration area. The development level of urbanization is mainly promoting the rapid development of industry agglomeration area in terms of capital, infrastructure, technology and human resources. In the meanwhile, urbanization development in industry agglomeration area may also attract more production companies, thereby increase the cultivation or introduction of all kinds of personnel, and improve the attractiveness of foreign investment institutions. Moreover, the development of urbanization will drive deep development of industry agglomeration area, thereby contribute to smooth inter-regional cooperation and improve market competitiveness of the industry agglomeration area.

\section{B. Condition of urbanization process provided for innovative industry agglomeration}

The support of research and development of science and technology and the development of urbanization promote the development of social economy and culture; enhance the scientific research strength of the enterprises and the financial ability of government. This provides the necessary material guarantee for further development of the second industry, the necessary material guarantee for improving production technology and product research and development [8]. 
The basic conditions of road construction, other infrastructure and the process of urbanization are infrastructure development, which are necessary conditions to the innovation of the existence and development of industry agglomeration area. The continuous improvement of infrastructure drive force for the economic development of innovative industry agglomeration, provide considerable external economic effects of innovative enterprises in the industry agglomeration area.

Urbanization provides a soft environment protection for innovational industry agglomeration, in which government plays an important role in construction of urbanization, provide many conveniences for the innovative industries, include not only the land, roads, drainage, heating and other hardware conditions, but also the improvement of investment environment, market competition environment, adequate supply of talents, and innovation system of soft conditions [9].

\section{The promotion of innovative industry agglomeration to urbanization}

First of all, the construction of innovative industry agglomeration is incentive for further development of urbanization. From development process of urbanization all over the world, development of urbanization is closely related to the development of industrialization, and the urbanization level increases with the level of industrialization. The American economists, like Kuznets and Chanari, investigate urbanization and industrialization about 100 countries from 1950-1970. The development of urbanization and industrialization is in S rising trend: in the early stage of industrialization, the development speed of industrialization is higher than urbanization, industrialization is the dynamic mechanism of economic and social development; in the middle stage of industrialization, the development of urbanization accelerates; when the urbanization rate reached $70 \%$, the urbanization speed began to slow down, that is to say, when the urbanization rate reached between $30 \%-70 \%$, the comprehensive effects of the urbanization development to economic society are far reaching than industrialization. And the development of industrialization mainly depends on the industry [10]. Innovative industry agglomeration area is the platform of the centralized development of industrial space, therefore, the construction of innovative industry agglomeration area guide to accumulation of industry, which leads to agglomeration effects and industrial development; provide space for the development of industrialization, so as to promote the development of industrialization. Industrial development will promote the development level of urbanization. Therefore, the innovative industry agglomeration is the space carrier of improving new urbanization level.

Secondly, the innovative industry agglomeration area is the platform of populated accumulation; innovative industrial industry agglomeration is not only concentrated in the space of the enterprise, but also spatial concentrated of population. High-quality labors are required in construction and development of innovative industry agglomeration area, which require a certain level of knowledge. New urbanization emphases on human resource, the urban-rural integration as the goal of the sustainable development strategy, finally realize the unity of city and countryside in political, economic, social and cultural. Therefore, with the progress of social civilization, urban residents have more educational opportunities, and the comprehensive quality can be improved. Thus, the development of urbanization is conducive to the construction and development of industry agglomeration area.

\section{CONCLUSION}

Urbanization is an inevitable result of the development of non-agricultural industries agglomeration, which takes industries as the main body. The core issue is changing employment structure, economic industry structure and urban and rural spatial structure. Urbanization process drives to improve the quality of labor, attract high-tech talents outside industry agglomeration, improve the technological absorption capacity of innovative industry agglomeration area, and then promote the development of innovative industry agglomeration area.

At the same time, dealing with the sustainable development issues of innovative industry agglomeration area and urbanization should be based on local conditions, effectively promote industrial centralization and intensive level. We should make full use of existing resources; promote the further development of domestic industrial development of urbanization, balanced development of cities and counties economic, social and living environment, so as to achieve healthy and rapid development of urbanization and innovative industries.

\section{REFERENCES}

[1] Vittorio Carlei,Massimiliano Nuccio. Mapping industrial patterns in spatial agglomeration: A SOM approach to Italian industrial districts[J]. Pattern Recognition Letters. 2014

[2] Andrew James Crawley,Stephen Hill. Is industrial agglomeration increasing? New evidence from a small open economy[J]. Journal of Economic Studies . 2011 (6)

[3] Manfred M. Fischer,Thomas Scherngell,Eva Jansenberger. Geographic localisation of knowledge spillovers: evidence from high-tech patent citations in Europe[J]. The Annals of Regional Science . 2009 (4)

[4] Hung-hsin Chen,Po-yen Lee,Tzyy-jane Lay. Drivers of dynamic learning and dynamic competitive capabilities in international strategic alliances[J]. Journal of Business Research . 2008 (12)

[5] Sukriye Yuksel. An Outlook of the Fashion Industry Through Fashion History[J]. Procedia - Social and Behavioral Sciences . 2012

[6] Dirk Pieter van Donk,Renzo Akkerman,Taco van der Vaart. Opportunities and realities of supply chain integration: the case of food manufacturers[J]. British Food Journal . 2008 (2)

[7] Kenneth A. Merchant,David T. Otley. A Review of the Literature on Control and Accountability[J]. Handbooks of Management Accounting Research . 2007

[8] Markham T. Frohlich. e - Integration in the Supply Chain: Barriers and Performance*[J]. Decision Sciences . 2007 (4)

[9] Holger Schiele. Location, location: the geography of industry clusters[J]. Journal of Business Strategy . 2008 (3)

[10] Renzo Akkerman,Dirk Pieter Donk. Analyzing scheduling in the food-processing industry: structure and tasks[J]. Cognition, Technology \& Work . 2009 (3) 